\title{
UNA EVALUACIÓN DE LOS PROCESOS EDUCATIVO-AMBIENTALES DE MANIZALES
}

\author{
Luz Elena Sepúlveda Gallego \\ Profesora Titular Universidad de Caldas \\ lesga@une.net.co
}

Manizales, 2009-05-06 (Rev. 2009-06-07)

\section{RESUMEN}

Se presenta la evaluación realizada de los procesos educativo-ambientales de la ciudad de Manizales específicamente relacionados con actividades de educación formal y no formal desarrolladas por organizaciones gubernamentales y no gubernamentales de la ciudad, incluidos los establecimientos de educación básica, media y superior; además, y como consecuencia de esta evaluación, se presenta una propuesta encaminada a lograr la inclusión de la dimensión ambiental en los procesos educativos del municipio.

\section{PALABRAS CLAVE}

Educación ambiental, Manizales, Ambiente.

\section{AN EVALUATION OF THE EDUCATIONAL-ENVIRONMENTAL PROCESSES IN MANIZALES}

\section{ABSTRACT}

The following article shows the evaluation of the educational-environmental processes in the city of Manizales (Colombia), specifically those related to activities of formal and nonformal education developed by governmental and non-governmental entities of the city, including elementary and high schools, and universities. Additionally, as a consequence of the mentioned evaluation, a proposal is suggested in order to achieve the inclusion of the environmental dimension in the educational processes of Manizales.

\section{KEY WORDS}

Environmental Education, Manizales, Environment.

\section{INTRODUCCIÓN}

La evidencia de la problemática ambiental del mundo y el grado de sensibilización frente a lo ambiental que en general se tiene, pueden caracterizar el momento actual como propicio para lograr que la educación ambiental llegue a consolidarse y a implementarse de manera adecuada. Si se acepta que la temática ambiental debe ser un saber de todos y para todos, y que la educación ambiental es un instrumento de gran utilidad para intervenir y prevenir los problemas ambientales, entonces, evaluar y proponer alternativas de solución frente a la implementación de procesos de educación ambiental formal y no formal se constituye en una necesidad, máxime cuando se reconoce que cada individuo, de una u otra manera, participa en la generación de los problemas ambientales y puede también ser partícipe de su solución.

Para darle cumplimiento a la normativa colombiana referente a los procesos educativoambientales se hace necesario que el sistema educativo de la ciudad incorpore la educación ambiental como elemento esencial de su quehacer, para lo cual se requiere 
conocer a cabalidad el estado actual de la situación y el grado de apropiación de la normativa. Esta evaluación permitiría determinar los logros y las deficiencias de dicha implementación y, también, elaborar propuestas conducentes a mantener los logros y a mejorar las deficiencias de los procesos.

Otro elemento que debe tenerse en cuenta es que Colombia le apuesta a las actividades intersectoriales mediante su legislación ambiental, educativa y sanitaria, lo cual exige la participación decidida y bien fundamentada del sistema educativo, incluyendo lo relacionado con los procesos de educación no formal y los propios del nivel superior o universitario.

En esta perspectiva, un proceso educativo caracterizado por la calidad requiere, como uno de sus aspectos fundamentales, estar contextualizado; es por ello que la educación tiene que mirar hacia el ambiente e involucrarse en él, tanto para conservarlo como para recuperarlo y disfrutarlo, es decir, hacer educación ambiental, educar en el ambiente, con el ambiente y para el ambiente, concibiendo éste en sus múltiples dimensiones.

La política de educación ambiental de Colombia tiene en cuenta la interrelación de tres grandes problemas que acosan no sólo al país sino al mundo entero: la pobreza, la violencia y la destrucción del medio ambiente. Partiendo del temor de que la destrucción antropogénica actual tenga la capacidad de producir una extinción masiva de las diferentes formas de vida, considera que la crisis ambiental se constituye en un detonante de la crisis civilizatoria; por lo cual encuentra la solución en un cambio cultural. Ante el desequilibrio ambiental producido por la forma de relación imperante entre humanidad y naturaleza, basada en un sistema tecnológico de explotación con una gran capacidad de transformación del entorno, la política propone generar una nueva racionalidad, capaz de cuestionar el actual modelo económico de crecimiento y los patrones tecnológicos vigentes. El logro de esta nueva racionalidad depende de que se asuman como tareas del sector educativo: la incorporación efectiva de nuevos valores éticos a la vida individual y colectiva y la estructuración de normas ambientales encaminadas a mitigar y prevenir los deterioros ambientales.

En este marco conceptual de la situación de los procesos educativo-ambientales, se realizó un proceso investigativo cuali-cuantitativo encaminado a evaluar el proceso educativo-ambiental de la ciudad de Manizales, a partir del estudio de los procesos relacionados realizados tanto a nivel del sistema educativo como de las organizaciones gubernamentales y no gubernamentales del municipio, y con miras a proponer alternativas para hacer realidad la inclusión de la dimensión ambiental en el sistema educativo de tal manera que se aprehenda el ambiente desde su multidimensionalidad para contribuir en la construcción participativa de ese anhelado país que logre el trato equitativo y justo para todos los colombianos y, en el marco de la soberanía nacional, el mantenimiento del soporte biofísico que hace posible nuestra supervivencia.

\section{MÉTODOS}

Para el desarrollo de esta investigación se combinaron métodos cualitativos y cuantitativos; para los primeros se utilizó el proceso de categorización emergente y, para los segundos, procesos convencionales de análisis estadístico que incluyeron la determinación de diferencias estadísticamente significativas mediante el estadístico chi cuadrado. La población objeto de estudio fueron las instancias gubernamentales y las organizaciones no gubernamentales que de alguna manera se relacionan con actividades de educación ambiental en el municipio de Manizales. Luego de analizar esta información desagregada se optó por generalizar los resultados a nivel municipal mediante la utilización de varias listas de chequeo con sus respectivas categorías de evaluación, aspecto éste que se desarrolla en este artículo.

\section{EVALUACIÓN}

En la siguiente tabla se presentan los objetivos de la educación ambiental contemplados en la Carta de Belgrado y, para cada uno de ellos, un comentario evaluativo referente a su 
cumplimiento en los procesos educativo-ambientales de la ciudad de Manizales y un juicio valorativo del mismo:

\begin{tabular}{|c|c|c|}
\hline OBJETIVOS & COMENTARIO & VALORACIÓN \\
\hline $\begin{array}{l}\text { Toma de conciencia. Ayudar a } \\
\text { las personas y a los grupos } \\
\text { sociales a que adquieran mayor } \\
\text { sensibilidad y conciencia del } \\
\text { medio ambiente en general y de } \\
\text { los problemas. }\end{array}$ & $\begin{array}{l}\text { Se ha tenido como objetivo en } \\
\text { todos los niveles educativos y } \\
\text { en el quehacer de las } \\
\text { instituciones relacionadas con el } \\
\text { tema; se han privilegiado las } \\
\text { actividades encaminadas a la } \\
\text { sensibilización. }\end{array}$ & $\begin{array}{l}\text { Insuficiente porque la } \\
\text { aprehensión de los } \\
\text { problemas ambientales no } \\
\text { obedece, en todos los } \\
\text { casos, a la perspectiva } \\
\text { sistémica y compleja del } \\
\text { ambiente. }\end{array}$ \\
\hline $\begin{array}{l}\text { Conocimientos. Ayudar a las } \\
\text { personas y a los grupos } \\
\text { sociales a adquirir una } \\
\text { comprensión básica del medio } \\
\text { ambiente en su totalidad, de los } \\
\text { problemas conexos y de la } \\
\text { presencia y función de la } \\
\text { humanidad en él, lo que entraña } \\
\text { una responsabilidad crítica. }\end{array}$ & $\begin{array}{l}\text { Se ha realizado mediante } \\
\text { procesos formativos formales en } \\
\text { la educación básica, media y } \\
\text { superior; también con la } \\
\text { comunidad general parte de las } \\
\text { organizaciones } \\
\text { gubernamentales y no } \\
\text { gubernamentales. }\end{array}$ & $\begin{array}{l}\text { Insuficiente porque los } \\
\text { textos de base que se } \\
\text { utilizan en la educación } \\
\text { básica tienen } \\
\text { imprecisiones y serios } \\
\text { problemas de } \\
\text { desactualización. }\end{array}$ \\
\hline $\begin{array}{l}\text { Actitudes. Ayudar a las } \\
\text { personas y a los grupos } \\
\text { sociales a adquirir valores } \\
\text { sociales y un profundo interés } \\
\text { por el medio ambiente que los } \\
\text { impulse a participar activamente } \\
\text { en su protección y } \\
\text { mejoramiento. }\end{array}$ & $\begin{array}{l}\text { Se ha realizado en grupos } \\
\text { aislados, de manera vinculada a } \\
\text { los procesos de sensibilización. }\end{array}$ & $\begin{array}{l}\text { Insuficiente porque la } \\
\text { participación activa no ha } \\
\text { sido el común } \\
\text { denominador de estos } \\
\text { procesos. }\end{array}$ \\
\hline $\begin{array}{l}\text { Aptitudes. Ayudar a las } \\
\text { personas y a los grupos } \\
\text { sociales a adquirir las aptitudes } \\
\text { necesarias para resolver los } \\
\text { problemas ambientales. }\end{array}$ & $\begin{array}{l}\text { Se ha realizado desde } \\
\text { organizaciones } \\
\text { gubernamentales y no } \\
\text { gubernamentales interesadas } \\
\text { en fomentar procesos de } \\
\text { participación y gestión } \\
\text { comunitaria. }\end{array}$ & $\begin{array}{l}\text { Insuficiente porque se ha } \\
\text { trabajado con grupos } \\
\text { aislados y ni siquiera } \\
\text { podría afirmarse que la } \\
\text { mayoría de la comunidad } \\
\text { manizaleña tiene esa } \\
\text { competencia. }\end{array}$ \\
\hline $\begin{array}{l}\text { Capacidad de evaluación. } \\
\text { Ayudar a las personas y a los } \\
\text { grupos sociales a evaluar las } \\
\text { medidas y los programas de } \\
\text { educación ambiental en función } \\
\text { de los factores ecológicos, } \\
\text { políticos, sociales, estéticos y } \\
\text { educativos. }\end{array}$ & $\begin{array}{l}\text { No se hace evidente el logro de } \\
\text { este objetivo en la mayoría de } \\
\text { las experiencias evaluadas. }\end{array}$ & $\begin{array}{l}\text { Insuficiente porque la } \\
\text { evaluación de los procesos } \\
\text { usualmente se refiere sólo } \\
\text { a la identificación de las } \\
\text { actividades realizadas } \\
\text { respecto a las } \\
\text { programadas. }\end{array}$ \\
\hline $\begin{array}{l}\text { Participación. Ayudar a las } \\
\text { personas y a los grupos } \\
\text { sociales a que desarrollen su } \\
\text { sentido de responsabilidad y a } \\
\text { que tomen conciencia de la } \\
\text { urgente necesidad de prestar } \\
\text { atención a los problemas del } \\
\text { medio ambiente, para asegurar } \\
\text { que se adopten medidas } \\
\text { adecuadas al respecto. }\end{array}$ & $\begin{array}{l}\text { Se ha realizado desde } \\
\text { organizaciones } \\
\text { gubernamentales y no } \\
\text { gubernamentales interesadas } \\
\text { en fomentar procesos de } \\
\text { participación y gestión } \\
\text { comunitaria. }\end{array}$ & $\begin{array}{l}\text { Insuficiente porque se ha } \\
\text { trabajado con grupos } \\
\text { aislados. }\end{array}$ \\
\hline
\end{tabular}

De esta manera, salvo algunas pocas excepciones, los procesos educativo-ambientales que se han desarrollado en la ciudad de Manizales logran de manera insuficiente los objetivos propuestos en Belgrado. Para superar esta situación se requiere que los procesos educativo-ambientales no sean producto sólo de la buena intención de un docente $o$ de un profesional vinculado a una organización gubernamental o no gubernamental; que los procesos involucren a toda la comunidad, con una clara y actualizada fundamentación científica y con la intencionalidad de generar un tipo de organización y participación comunitaria que permita el trabajo mancomunado en pro de la calidad de vida y del ambiente.

Para continuar con la evaluación global de los procesos educativos-ambientales de Manizales, en la siguiente tabla se presenta un comentario general para cada uno de los 
principios de la educación ambiental que se propusieron en el Tratado sobre Educación Ambiental para Sociedades Sustentables y Responsabilidad Global en Río de Janeiro:

\begin{tabular}{|c|c|}
\hline PRINCIPIO & COMETARIO \\
\hline $\begin{array}{l}\text { La educación es un derecho de todos; somos todos } \\
\text { educandos y educadores. }\end{array}$ & $\begin{array}{l}\text { Principio aplicado desde la perspectiva } \\
\text { constitucional, pero aún no logrado en la } \\
\text { realidad. }\end{array}$ \\
\hline $\begin{array}{l}\text { La educación ambiental debe tener como base el } \\
\text { pensamiento crítico e innovador, en cualquier tiempo y } \\
\text { lugar, en sus expresiones formal, no formal e informal, } \\
\text { promoviendo la transformación y la construcción de la } \\
\text { sociedad. }\end{array}$ & $\begin{array}{l}\text { Principio aplicado desde la } \\
\text { intencionalidad de la norma, pero no } \\
\text { logrado en la realidad. El pensamiento } \\
\text { crítico en situaciones políticas tan tensas } \\
\text { como las que vive el país se convierte en } \\
\text { un factor de riesgo para la vida de las } \\
\text { personas. }\end{array}$ \\
\hline $\begin{array}{l}\text { La educación ambiental es individual y colectiva. Tiene } \\
\text { el propósito de formar ciudadanos con conciencia local } \\
\text { y planetaria, que respeten la autodeterminación de los } \\
\text { pueblos y la soberanía de las naciones. }\end{array}$ & $\begin{array}{l}\text { Principio aplicado parcialmente en tanto } \\
\text { todo el potencial del mismo sólo podría } \\
\text { existir en el marco del pensamiento } \\
\text { crítico y transformador. }\end{array}$ \\
\hline $\begin{array}{l}\text { La educación ambiental no es neutra, sino ideológica. } \\
\text { Es un acto político, basado en valores para la } \\
\text { transformación social. }\end{array}$ & $\begin{array}{l}\text { Principio escasamente reconocido y } \\
\text { ampliamente temido. }\end{array}$ \\
\hline $\begin{array}{l}\text { La educación ambiental debe tener una perspectiva } \\
\text { holística, enfocando la relación entre el ser humano, la } \\
\text { naturaleza y el universo, de forma interdisciplinaria. }\end{array}$ & $\begin{array}{l}\text { Principio aplicado parcialmente en los } \\
\text { procesos educativo-ambientales tanto de } \\
\text { organizaciones gubernamentales como } \\
\text { no gubernamentales. }\end{array}$ \\
\hline $\begin{array}{l}\text { La educación ambiental debe estimular la solidaridad, } \\
\text { la igualdad y el respeto a los derechos humanos, } \\
\text { valiéndose de estrategias democráticas e interacción } \\
\text { entre las culturas. }\end{array}$ & $\begin{array}{l}\text { Principio contemplado por los procesos } \\
\text { educativo-ambientales de la ciudad, pero } \\
\text { limitado por el fenómeno sociopolítico del } \\
\text { país. }\end{array}$ \\
\hline $\begin{array}{l}\text { La educación ambiental debe tratar las cuestiones } \\
\text { mundiales críticas, sus causas e interrelaciones en una } \\
\text { perspectiva sistémica, en su contexto social e histórico. } \\
\text { Aspectos primordiales relacionados con su desarrollo y } \\
\text { su medio ambiente tales como, población, paz, } \\
\text { derechos humanos, democracia, salud, hambre, } \\
\text { deterioro de la flora y fauna deben ser abordados de } \\
\text { esta manera. }\end{array}$ & $\begin{array}{l}\text { Principio aplicado parcialmente en tanto } \\
\text { el enfoque de los procesos educativo- } \\
\text { ambientales de la ciudad le apuntan más } \\
\text { a la problemática local. }\end{array}$ \\
\hline $\begin{array}{l}\text { La educación ambiental debe facilitar la cooperación } \\
\text { mutua y equitativa en los procesos de decisión en } \\
\text { todos los niveles y etapas. }\end{array}$ & $\begin{array}{l}\text { Principio aplicado parcialmente en el } \\
\text { marco del conocimiento de los derechos } \\
\text { colectivos y su forma de intervención, } \\
\text { pero limitado por el difícil acceso a la } \\
\text { información ambiental. }\end{array}$ \\
\hline $\begin{array}{l}\text { La educación ambiental debe recuperar, reconocer, } \\
\text { respetar, reflejar y utilizar la historia indígena y las } \\
\text { culturas locales, así como promover la diversidad } \\
\text { cultural, lingüística y ecológica. }\end{array}$ & $\begin{array}{l}\text { Principio aplicado desde la normativa } \\
\text { nacional. }\end{array}$ \\
\hline $\begin{array}{l}\text { La educación ambiental debe estimular y potencializar } \\
\text { el poder de las diversas poblaciones, promover } \\
\text { oportunidades para los cambios democráticos de base } \\
\text { que estimulen a los sectores populares de la sociedad. } \\
\text { Esto implica que las comunidades deben retomar la } \\
\text { conducción de sus propios destinos. }\end{array}$ & $\begin{array}{l}\text { Principio no aplicado en tanto los } \\
\text { procesos educativo-ambientales no han } \\
\text { logrado generar una verdadera } \\
\text { organización comunitaria conducente a la } \\
\text { participación activa en pro de la real toma } \\
\text { de decisiones. }\end{array}$ \\
\hline $\begin{array}{l}\text { La educación ambiental valoriza las diferentes formas } \\
\text { de conocimientos. Este es diversificado, acumulado y } \\
\text { producido socialmente, y no deberá ser patentado ni } \\
\text { monopolizado. }\end{array}$ & Principio aplicado desde la normativa. \\
\hline $\begin{array}{l}\text { La educación ambiental debe ser planificada para } \\
\text { capacitar a las personas para resolver conflictos de } \\
\text { manera justa y humana. }\end{array}$ & $\begin{array}{l}\text { Principio parciamente aplicado en tanto } \\
\text { la normativa específica se produjo sin un } \\
\text { cuerpo docente adecuadamente } \\
\text { capacitado para ello. }\end{array}$ \\
\hline $\begin{array}{l}\text { La educación ambiental debe promover la cooperación } \\
\text { y el diálogo entre individuos e instituciones, con la } \\
\text { finalidad de crear nuevos modos de vida, fundados en } \\
\text { la comprensión de las necesidades básicas de todos, } \\
\text { sin distinciones étnicas, físicas, de género, edad, } \\
\text { religión, clase, mentales, etc. }\end{array}$ & $\begin{array}{l}\text { Principio aplicado desde la normativa y el } \\
\text { funcionamiento de la estructura sostén } \\
\text { de la educación ambiental, pero limitado } \\
\text { por aspectos culturales discriminadores. }\end{array}$ \\
\hline $\begin{array}{l}\text { La educación ambiental requiere la democratización de } \\
\text { los medios de comunicación masivos y su compromiso } \\
\text { con los intereses de todos los sectores de la sociedad. }\end{array}$ & Principio no aplicado. \\
\hline
\end{tabular}




\begin{tabular}{|l|l|}
\hline PRINCIPIO & COMETARIO \\
\hline $\begin{array}{l}\text { La educación ambiental debe integrar conocimientos, } \\
\text { aptitudes, valores, actitudes y acciones. Debe convertir } \\
\text { cada oportunidad en experiencias educativas para } \\
\text { sociedades sustentables. }\end{array}$ & $\begin{array}{l}\text { Principio aplicado desde la normativa y } \\
\text { desde la intencionalidad de la mayoría de } \\
\text { los procesos educativo-ambientales. }\end{array}$ \\
\hline $\begin{array}{l}\text { La educación ambiental debe ayudar a desarrollar una } \\
\text { conciencia ética sobre todas las formas de vida con las } \\
\text { cuales compartimos este planeta; respetar sus ciclos } \\
\text { vitales e imponer límites a la explotación de esas } \\
\text { formas de vida por los seres humanos. }\end{array}$ & $\begin{array}{l}\text { Principio aplicado desde la normativa y } \\
\text { desde la intencionalidad de la mayoría de } \\
\text { los procesos educativo-ambientales. }\end{array}$ \\
\hline
\end{tabular}

En la educación ambiental de Manizales se evidencia la aplicación de algunos de los principios del Tratado desde las normas que trazan el camino por seguir en las diferentes instituciones y, por ende, desde las justificaciones e intencionalidades de los diferentes procesos; no obstante, el desarrollo de esos procesos denota que los principios definidos no siempre se reflejan en la cotidianidad de su realización.

Algunos de los principios, específicamente aquellos relacionados con posiciones políticas y con el ideal de una Escuela emancipadora, no se han aplicado o se han aplicado parcialmente, pues incorporar en el discurso una educación ambiental con fundamento ideológico y tendiente a lograr la transformación social es arriesgado y mal visto por un alto porcentaje de compatriotas.

Al menos para el caso colombiano, otra alternativa para evaluar los procesos educativoambientales en el sistema educativo formal, consiste en la determinación del grado de sostenibilidad de los proyectos ambientales escolares. Para ello, se hace uso de cinco de los factores de sostenibilidad conceptualizados por el Ministerio de Educación Nacional:

\begin{tabular}{|c|c|c|}
\hline FACTOR & COMENTARIO & EVALUACIÓN \\
\hline $\begin{array}{l}\text { Los equipos de docentes y/o } \\
\text { dinamizadores que los lideran se han } \\
\text { venido acompañando a través de } \\
\text { procesos, sistemáticos y secuenciales, } \\
\text { de capacitación-formación que } \\
\text { reconocen las problemáticas } \\
\text { ambientales y educativas del contexto } \\
\text { local. }\end{array}$ & $\begin{array}{l}\text { El acompañamiento no ha sido } \\
\text { generalizado; la consolidación de } \\
\text { unos pocos proyectos } \\
\text { ambientales escolares no es } \\
\text { suficiente como para reconocer } \\
\text { el éxito de la estrategia en la } \\
\text { ciudad. }\end{array}$ & Insuficiente \\
\hline $\begin{array}{l}\text { Han logrado incorporar la problemática } \\
\text { ambiental de contexto como eje } \\
\text { transversal de las propuestas } \\
\text { formativas de los PEI. }\end{array}$ & $\begin{array}{l}\text { Para la mayoría de los } \\
\text { establecimientos educativos el } \\
\text { proyecto ambiental escolar es un } \\
\text { elemento adicional al proyecto } \\
\text { educativo institucional. }\end{array}$ & Casi nulo \\
\hline $\begin{array}{l}\text { Han construido propuestas } \\
\text { pedagógico-didácticas que favorecen } \\
\text { el conocimiento significativo, desde las } \\
\text { competencias ciudadanas y de } \\
\text { pensamiento científico. }\end{array}$ & $\begin{array}{l}\text { En la mayoría de las instituciones } \\
\text { que cuentan con proyecto } \\
\text { ambiental escolar, éste no ha } \\
\text { generado cambios curriculares } \\
\text { de fondo ni propuestas } \\
\text { pedagógico didácticas } \\
\text { innovadoras. }\end{array}$ & Insuficiente \\
\hline $\begin{array}{l}\text { Se han posicionado como estrategias } \\
\text { de articulación del trabajo } \\
\text { interinstitucional, en los planes, } \\
\text { programas, propuestas de las } \\
\text { Secretarías de Educación y de las } \\
\text { Corporaciones Autónomas Regionales, } \\
\text { fundamentalmente. }\end{array}$ & $\begin{array}{l}\text { La estrategia referente a la } \\
\text { elaboración y ejecución de } \\
\text { proyectos ambientales escolares } \\
\text { es bien acogida por parte del } \\
\text { sector gubernamental de la } \\
\text { ciudad. }\end{array}$ & Adecuado \\
\hline $\begin{array}{l}\text { Han sido permanentemente } \\
\text { acompañadas, tanto en lo técnico } \\
\text { como en lo financiero por los Comités } \\
\text { Técnicos Interinstitucionales de } \\
\text { Educación Ambiental. }\end{array}$ & $\begin{array}{l}\text { El Comité Técnico de Educación } \\
\text { Ambiental aún no ha llegado a la } \\
\text { fase de acompañar técnica y } \\
\text { financieramente los proyectos } \\
\text { ambientales escolares. }\end{array}$ & Nulo \\
\hline
\end{tabular}

El único factor a favor de la sostenibilidad de los proyectos ambientales escolares en la ciudad de Manizales es la aceptación de la estrategia por parte de las entidades 
gubernamentales, para las cuales no queda ninguna otra alternativa, en la medida que deben seguir los lineamientos nacionales como parte inherente de sus funciones. Los demás factores muestran el altísimo riesgo que se está corriendo al apostarle a esta estrategia si lo que se desea realmente es tener una comunidad adecuadamente conocedora del ambiente, de sus potencialidades, de las causas y consecuencias de sus problemas y de las formas y requerimientos necesarios para solucionarlos. La capacitación de los docentes se ha reducido a grupos pequeños y no se ha logrado continuidad. A nivel de las instituciones educativas el proyecto ambiental escolar sigue siendo una tarea más por la cual hay que responder y no un pretexto para darle a la Escuela la dimensión social que amerita.

\section{A MANERA DE CONCLUSIONES}

- Existe un desfase entre los avances conceptuales de la educación ambiental y su aplicación en procesos educativo-ambientales concretos y verificables, cuya solución está en modificar los procesos de formación de formadores en tanto la perspectiva sistémica y compleja del ambiente no se aprehende de la simple recepción de información, se requiere involucrada en el proceso de formación del profesional. De aquí se deriva que el punto de partida para hacer realidad los avances conceptuales antes mencionados consiste en dirigir los esfuerzos hacia la inclusión de la dimensión ambiental en los procesos formativos universitarios.

- La conceptualización que actualmente se tiene de la educación ambiental insinúa la necesidad de caracterizar todos los procesos educativos como educativo-ambientales, lo cual podría lograrse con modificaciones normativas conducentes a entender a nivel estatal la necesidad de abrir la Escuela a la sociedad y de resignificar el proyecto educativo institucional para que sea inherentemente ambiental y así los proyectos ambientales escolares no se constituyan en un trabajo adicional y paralelo al cumplimiento de la misión de la institución. No es concebible una educación de calidad si los procesos formativos no tienen una clara intencionalidad educativo-ambiental.

- Los procesos educativo-ambientales requieren el desarrollo de la capacidad de analizar críticamente y desde una perspectiva interdisciplinar los diferentes fenómenos y situaciones socio-culturales-ambientales, con lo cual no pueden ser iguales para los diferentes lugares del mundo ni para todos los habitantes del planeta; deben diferenciarse de acuerdo al grado de responsabilidad de cada grupo humano frente al deterioro y la crisis ambiental.

- Los medios de comunicación son un elemento clave para lograr la difusión de información y el cambio de comportamiento ligados a procesos educativo-ambientales en tanto tienen un gran poder para reforzarlos o, como ocurre frecuentemente, de opacarlos, dado su interés económico de inducción al consumo.

- La educación ambiental implica que la escuela acepte su compromiso social con la comunidad educativa, lo cual sólo puede lograrse en la medida en que tenga una apertura en su quehacer y supere el trabajo de aula aislado de la realidad social de los estudiantes.

- La orientación de los proyectos ambientales escolares únicamente hacia la problemática ambiental local que pueda ser intervenida por las instituciones educativas y su comunidad educativa, de manera interinstitucional con otras entidades de la localidad, deja de lado grandes problemas socioambientales que encuentran solución en la modificación del modelo de desarrollo del país, cuya intervención seguramente redundaría en el bienestar de los habitantes de cada localidad.

- Para que los maestros tengan la posibilidad de liderar una escuela abierta, comprometida con la realidad social, cultural y natural de su localidad, se requiere un compromiso estatal que financie los tiempos y espacios requeridos para ello. La 'optimización' de la planta de docentes (mayor número de estudiantes y de horas cátedra con el mismo o menor número de docentes) hace que se tomen medidas en contra de favorecer procesos de pensamiento y de creatividad, así como de organización comunitaria. 
- La meta de la educación ambiental debería ser la formación de todas las personas, de tal forma que se comprometan solidariamente con la calidad de vida de todos los habitantes del planeta y con la estabilidad del medio ambiente, y que tengan conocimiento, aptitud, actitud, motivación y compromiso para asumir y aceptar el principio de precaución y trabajar individual y colectivamente en la búsqueda de soluciones para los problemas existentes y para prevenir nuevos.

- Una educación ambiental bien concebida es inevitablemente, en países en desarrollo, una educación para la emancipación, lo cual la hace peligrosa para los intereses de los dueños de los grandes capitales nacionales.

\section{A MANERA DE PROPUESTA}

Tal y como se afirma en la Declaración de Buenos Aires en Formación Ambiental, "la educación ambiental no debe constituirse en un instrumento más del modelo de desarrollo imperante, que difunde la creencia mística que el desarrollo tecnológico todo lo puede y todo lo resuelve, y que el mismo logrará un uso más racional de los recursos naturales del planeta para poder seguir produciendo bienes y servicios"1 ${ }^{1}$, de tal manera que lo requerido es "resignificar la crisis ambiental como una crisis de conocimiento, descolonizando las prácticas educativas, para concebir la enseñanza como una actividad crítica, como una práctica social donde se conjugan múltiples opciones de carácter ético y se pone en práctica un diálogo de saberes en la construcción de un futuro sustentable, equitativo y diverso"2. Es por ello que aquí se considera como paso fundamental para lograr una verdadera y comprometida educación ambiental, influir en los procesos formativos de los futuros profesionales.

Para empezar, a pesar de que está claro que una asignatura no soluciona el problema, desde la evaluación realizada la única alternativa viable y factible en este momento sería, justamente, la obligatoriedad de incluir en los planes de estudio de todos los programas académicos una actividad académica que: a) desde los conocimientos más actualizados, lleve al estudiante a reconocer la improbabilidad del fenómeno vida $\mathrm{y}$, por ende, su valoración intrínseca tanto del fenómeno en sí como del propio de cada una de las expresiones de la biodiversidad con las que cohabitamos este planeta; b) le permita al estudiante aproximarse a los problemas ambientales globales y a su repercusión a nivel nacional y local, pero con una fundamentación política, económica y sociológica suficiente para entender críticamente las causas de estas problemáticas tanto desde la perspectiva nacional como desde y en las relaciones internacionales a que está sometido nuestro país; c) le dé al estudiante elementos de economía suficientemente sólidos como para entender el por qué y el para qué de la economía convencional, así como los fundamentos y las implicaciones sociopolíticas y científicas inherentes a la economía entendida como ambiental y como ecológica; d) trabaje con el estudiante la incorporación del principio de precaución en su cotidianidad, para lo cual se requiere poner en cuestión la certeza, la ciencia y la tecnología, sus avances y sus tendencias; e) le permita al estudiante conocer y analizar los fundamentos y las implicaciones del actual modelo de desarrollo del país tanto en su perspectiva interna como en la internacional, bajo la perspectiva del valor estratégico y de recursos naturales que caracteriza a Colombia; f) propicie en el estudiante el entendimiento del fenómeno de la pobreza y la exclusión en el mundo y en el país, de tal manera que le genere compromisos presentes y futuros para luchar en pro de la igualdad de oportunidades y la justicia social para todos; g) genere en el estudiante el convencimiento de que parte de su futuro actuar profesional deberá estar enfocado a ser un educador ambiental con todas y cada una de las personas con las que entre en contacto, como uno de los mecanismos de revertirle a la sociedad lo que ella le aportó en su proceso formativo; y h) fomente en el estudiante la necesidad de agremiación y asociación para que, por medio de ella y de las herramientas constitucionales de participación, se entiendan como forjadores del futuro y con potencial para contribuir en la transformación política, social y económica que se requiere. El ejemplo de cómo incluir una asignatura en los procesos formativos universitarios está dado con obligatoriedad definida en la Ley 30 de 1992 de enseñar Constitución Política de Colombia; el camino recorrido con esta experiencia podría retomarse para la propuesta de asignatura mencionada. 
Podría argumentarse en contra de la propuesta de asignatura la necesidad, seguramente ya demostrada, de que todas las actividades académicas se permeen por lo ambiental, es decir, que se logre una verdadera inclusión de la dimensión ambiental en los diferentes procesos formativos. Pero, si reconocemos y aceptamos la perspectiva sistémica y compleja del ambiente tendríamos que aceptar también que actualmente los procesos formativos incluyen la dimensión ambiental. El asunto es que la mirada ambiental está incorporada pero desde su perspectiva antropocéntrica y utilitarista, al servicio de los grandes intereses económicos nacionales, internacionales y multinacionales. Lo que se requiere pues es un cambio en el enfoque, lo que para muchos sería considerado como un acto revolucionario o emancipador que, superando las tendencias mass mediáticas del consumo por el consumo y el entendimiento de la pobreza como un efecto residual del modelo de desarrollo, tendría el potencial para generar verdaderas transformaciones sociales.

Teniendo en cuenta que la mayoría de los maestros de la educación básica y media son licenciados graduados en las universidades, podría pensarse como una alternativa útil para lograr el compromiso de las instituciones universitarias con la formación ambiental de sus futuros egresados, la inclusión en los criterios para otorgar registro calificado y acreditación de alta calidad de la demostración del abordaje de la temática ambiental desde sus componentes sociales, políticos y económicos en los procesos formativos. El asunto aquí es que los entes reguladores de la educación superior están enmarcados en los principios e intencionalidades del modelo de desarrollo vigente, con lo cual la posibilidad de que propendan por una educación superior crítica y, seguramente, opuesta al modelo de desarrollo que les da su estatus social, es mínima.

Las categorías básicas que podrían utilizarse para determinar el grado de inclusión de la dimensión ambiental en las actividades universitarias podrían ser: abordaje interdisciplinario, visión crítica y analítica de la ciencia y la tecnología, fundamentación ética no antropocéntrica, análisis socioambiental y calidad de vida.

Con profesionales adecuadamente formados, o al menos críticamente informados, podría pensarse en transformar el sistema educativo, tal y como lo exige la implementación de unos procesos educativo-ambientales fundamentados en la relación sociedad-culturanaturaleza.

A nivel normativo nacional y, si no es posible, a nivel del municipio, debería entenderse que el proyecto educativo institucional es el que debe garantizar la inclusión de la dimensión ambiental en el quehacer educativo y no el proyecto ambiental escolar pues éste, al menos en el futuro próximo y en la ciudad de Manizales, no dejará de ser un proyecto adicional sin la suficiente injerencia como para modificar elementos curriculares de la institución. La normativa nacional sobre los proyectos educativos institucionales genera una oportunidad valiosísima, pues el proyecto además de ser obligatorio debe tener en cuenta las condiciones sociales, económicas y culturales de su medio, a lo cual faltaría agregarle las condiciones naturales y las interrelaciones entre todas ellas. La construcción participativa y contextualizada del proyecto educativo institucional en la que, inevitablemente, estarían involucrados los directivos docentes y todos los maestros del establecimiento educativo genera la posibilidad de establecer unos principios y fundamentos de la acción educativa correspondientes con la situación ambiental global y los que se pueda apoyar la institución para convertirla en un punto de encuentro, de pensamiento, de difusión, de compromiso y de propuestas relacionadas con la mejoría de la calidad de vida de su comunidad educativa. Si el proyecto educativo institucional es ambiental, y los procesos formativos y curriculares de la institución obedecen al proyecto educativo institucional, entonces la alternativa para que estos procesos estén realmente permeados por la deseada dimensión ambiental es modificar de fondo los proyectos educativos institucionales.

Los diferentes elementos que debe contemplar un proyecto educativo institucional como el manual de convivencia, el gobierno escolar y el servicio social del estudiantado, deberían entenderse como una puesta en escena de los valores y principios ambientales que, desde el nivel conceptual, pretende la educación ambiental. Como se ve, la propuesta es que los proyectos educativos institucionales se elaboren en, desde y para la situación social, política, económica, cultural y natural de la comunidad educativa en pro de su 
transformación hacia una sociedad equitativa, justa y reconocedora del valor de la vida en todas sus expresiones.

Los procesos de capacitación de docentes que realiza el Ministerio de Educación Nacional, o en su defecto los que realice la Secretaría de Educación de Manizales, deberían enfocarse, en primera instancia, a la capacitación de los directivos docentes, específicamente de los rectores, en tanto su formación inicial seguramente obedeció al tipo de procesos formativos ya criticados y, para entender la dimensión ambiental y sus implicaciones sociales, económicas y políticas tendrían que desaprender lo aprendido para darle cabida a otros enfoques y perspectivas de la situación. La apuesta por la inclusión de la dimensión ambiental en el quehacer escolar requiere de la toma de decisiones que necesariamente tienen que ver con los directivos de la institución; al respecto, es importante reconocer que los intentos transformadores de un solo profesor o de un pequeño grupo de profesores no son suficientes como para lograr un profundo cambio en el proceso educativo.

Mientras llegan profesionales debidamente formados desde la perspectiva ambiental a ocupar los cargos administrativos y operativos de las diferentes organizaciones gubernamentales y no gubernamentales que de alguna manera debieran relacionarse con los procesos educativo-ambientales de los habitantes de Manizales, sería necesario emprender un proceso de cualificación de los profesionales que actualmente ocupan estos cargos; esta decisión podría ser tomada por Concejo municipal o por la Alcaldía pero, claro está, primero sería necesario realizar un proceso formativo profundo con el equipo de concejales y el alcalde de la ciudad. Las diferentes tendencias políticas seguramente harían su aparición a favor o en contra de los diferentes aspectos relacionados con los asuntos ambientales lo cual podría dificultar considerablemente el proceso formativo; visto desde otro ángulo, la diversidad de posturas y opiniones que pueda generar sería de por sí la antesala al conocimiento de qué tan factible es que el quehacer gubernamental de la ciudad se comprometa con el cumplimiento de los principios y los objetivos de la educación ambiental.

En el marco de la Política Nacional de Educación Ambiental, podría pensarse en apostarle al Comité Técnico de Educación Ambiental de Manizales como instancia asesora y responsable de los procesos educativo-ambientales de la ciudad siempre y cuando: a) esté constituido por todas las organizaciones constituyentes del Sistema Nacional Ambiental a nivel del municipio y todas las demás, tanto gubernamentales como no gubernamentales que de una u otra manera se relacionen con procesos educativoambientales; b) los delegados de las diferentes instituciones sean conocedores de la temática ambiental y educativo-ambiental desde las perspectivas específicas de sus formaciones; c) la delegación institucional lleve implícita la posibilidad de adquirir compromisos desde la institución, es decir, que la delegación tenga una vía directa de acceso a las instancias directivas de las respectivas instituciones; d) los delegados tengan disponibilidad suficiente de tiempo para, además de asistir a las reuniones, realizar las actividades derivadas de las mismas, con reconocimiento en su jornada laboral; e) se vele por la permanencia de los delegados si cumplen adecuadamente con sus funciones; esto implicaría el establecimiento de un sistema de evaluación que permitiera determinar la presencia o no de esta característica en los diferentes delegados y, claro está, el reconocimiento de la evaluación por parte de las diferentes instituciones de tal manera que actúen en consecuencia; y f) ubicar al Comité administrativamente en un lugar jerárquico que le brinde autonomía, reconocimiento y posibilidad de tomar decisiones pues se requeriría constituirlo en la instancia responsable de conocer, evaluar y autorizar o no las actividades educativo-ambientales propuestas por las diferentes instancias, incluido el Plan de Desarrollo de la ciudad.

Finalmente, y a manera de reflexión, vale la pena al menos insinuar la necesidad de releer las propuestas ministeriales para dilucidar ¿cuál es la explicación de haber destinado la mayor parte de los esfuerzos a conceptualizar sobre la inclusión de la dimensión ambiental en las zonas rurales y pequeño urbanas del país?; ¿por qué el énfasis en proyectos ambientales escolares centrados en la problemática local sin un análisis profundo e interdisciplinario de la misma en el plano histórico e internacional?; ¿por qué se privilegia el estudio de los recursos naturales de la zona como inicio para la formulación de los proyectos ambientales escolares?; si está tan claro que la educación ambiental lo 
que pretende es transformar el sistema educativo, ¿por qué no se enfoca la propuesta a este objetivo? El modelo de desarrollo de nuestro país subsume la educación ambiental pero le corta las alas, y lo hace porque si la dejara volar ella lo cuestionaría y, seguramente, lo modificaría de manera profunda.

\section{BIBLIOGRAFÍA}

- COlOMBia. MiNISTERIO dE EDUCACIÓN NACIONAL. Memorias del seminario internacional "La dimensión ambiental y la escuela". Santafé de Bogotá: El Ministerio, FES, 1994

- COlOMBIA. CONGRESO DE LA REPÚBliCA. Constitución Política de Colombia de 1991.

- COlOMBIA. CONGRESO DE LA REPÚBLICA. Ley 115 de 1994.

- COlOMBIA. CONGRESO DE LA REPÚBLICA. Ley 30 de 1992.

- $\quad$ COLOMBIA. CONGRESO DE LA REPÚBLICA. Ley 715 de 2002.

- $\quad$ COLOMBIA. CONGRESO DE LA REPÚBLICA. Ley 99 de 1993.

- COLOMBIA. MINISTERIO DE EDUCACIÓN NACIONAL. Estándares básicos de competencias en lenguaje, matemáticas, ciencias y ciudadanas. Bogotá: El Ministerio, 2006.

- COlOMBIA. MINISTERIO DE EDUCACIÓN NACIONAL. MINISTERIO DEL MEDIO AMBIENTE. Reflexión y acción: el diálogo fundamental para la educación ambiental. Bogotá: Los Ministerios, 2002.

- COlOMBIA. MINISTERIO DEL MEDIO AMBIENTE. CONSEJO NACIONAL AMBIENTAL. DEPARTAMENTO NACIONAL DE PLANEACIÓN. COLCIENCIAS. Política Nacional de Investigación Ambiental. Bogotá: El Ministerio, 2001.

- COlOMBIA. MINISTERIO DEL MEDIO AMBIENTE. MINISTERIO DE EDUCACIÓN NACIONAL. Política Nacional de Educación Ambiental. Bogotá: Los Ministerios, 2002.

- $\quad$ COlOMBIA. PRESIDENCIA DE LA REPÚBLICA. Decreto 1743 de 1994.

- COlOMBiA. PRESIDENCIA DE LA REPÚBLICA. Decreto 1860 de 1994

- COLOMBIA. Visión Colombia II Centenario.

- COMité tÉCNICO dE EduCACIÓn AMBIENTAL DE CALDAS. Plan para la ambientalización de la educación en Caldas 2007-2019, noviembre de 2007.

- departamento nacional de PlaneAcion. Proyecto PROEQUIDAD GTZ. Género, equidad y desarrollo. Santafé de Bogotá: Tercer Mundo, 1998.

- $\quad$ http://www.alcaldiamanizales.gov.co

- http://www.colombiaaprende.edu.co/html/mediateca/1607/article-81637.html

- http://www.geocities.com/smpmanizales/mzlseducacion.htm

- MANIZALES. CONSEJO DE MANIZALES. Acuerdo 0680 de junio de 2008.

- NACIONES UNIDAS. CONFERENCIA DE LAS NACIONES UNIDAS SOBRE EL MEDIO AMBIENTE. Declaración de Estocolmo, Suecia, 5-16 de junio de 1972.

- NACIONES UNIDAS. CONFERENCIA DE LAS NACIONES UNIDAS SOBRE EL MEDIO AMBIENTE Y EL DESARROLLO. Declaración de Río. Río de Janeiro, República Federativa del Brasil - junio de 1992.

- NACIONES UNIDAS. CONFERENCIA DE LAS NACIONES UNIDAS SOBRE EL MEDIO AMBIENTE Y EL DESARROLLO. Agenda 21. Río de Janeiro, República Federativa del Brasil - junio de 1992.

- Seminario Iberoamericano de Formación Ambiental Buenos Aires, 21 y 22 de septiembre de 2005.

- Seminario Internacional de Educación Ambiental. Belgrado, 13 al 22 de octubre de 1975.

- $\quad$ TOBASURA, Isaías y SEPÚLVEDA, Luz Elena. Proyectos ambientales escolares. Estrategia para la formación ambiental. Santafé de Bogotá: Magisterio, 1997. 


\section{NOTAS}

1. Seminario Iberoamericano de Formación Ambiental Buenos Aires, 21 y 22 de septiembre de 2005. p. 2.

2. Ibidem. 